\title{
Comorbidities of asthma during childhood: possibly important, yet poorly studied
}

\author{
E.P. de Groot*, E.J. Duiverman" and P.L.P. Brand*,"
}

ABSTRACT: Asthma in adults is associated with comorbidities such as obesity, gastrooesophageal reflux, dysfunctional breathing and mental disorders. Herein, we provide an overview of the current state of evidence on these comorbidities in childhood asthma. The prevalence, known mechanisms and possible treatment options for each comorbid condition will be discussed.

Obesity is an increasing health problem in children, but its relationship with asthma remains unclear. Allergic rhinitis is a very common comorbidity in asthma, both in children and in adults, but its effect on childhood asthma severity has not been studied. The prevalence and treatment options of dysfunctional breathing, a known comorbidity in adult asthma, have not yet been studied in paediatric asthma. Food allergies appear to cause more severe reactions in patients with asthma. Depressive disorders are more prevalent in childhood asthma than in healthy children, but seem to be poorly recognised and treated in children. Although gastro-oesophageal reflux is commonly thought to be a comorbid disease complicating asthma, it remains uncertain whether treatment improves asthma control.

In conclusion, knowledge of asthma comorbidities in childhood is sparse. Further studies are urgently needed to identify the prevalence, and, more importantly, the effects of these comorbidities and their treatment on the degree of asthma control in children.

KEYWORDS: Asthma, childhood, comorbidity prevalence, diagnosis, treatment

$\mathbf{T}$ he guidelines on the diagnosis and management of asthma focus on achieving and maintaining asthma control as the key goal in asthma treatment $[1,2]$. Asthma control can be defined as the extent to which various manifestations of asthma have been reduced or resolved by treatment [3].

In clinical studies of children with asthma, reported in guidelines and reviews, satisfactory asthma control can be achieved and maintained in most patients by regular treatment with inhaled corticosteroids (ICS) [4, 5]. Large population-based surveys, however, consistently show that poor asthma control is common in many children with asthma, despite ICS treatment [6-8]. In the $17 \mathrm{yrs}$ since the inception of the first international asthma guidelines, hospitalisation rates, emergency department visits and deaths from asthma have remained stable in the USA [9]. The situation in Europe is more complex. Studies from Scandinavia between 1980 and 2000 have shown a decrease in asthma hospitalisation days and a trend towards fewer admissions for childhood asthma [10-15]. In Greece, however, hospitalisations for asthma increased during the same study period [16].

The reasons for this striking paradox between ICS efficacy in clinical trials and the ongoing morbidity in asthmatic children treated with ICS in daily practice remain largely unclear. Only recently have investigators started to explore its potential contributing factors. It appears that poor inhalation technique [17], poor adherence to ICS [18]

\section{AFFILIATIONS}

*Princess Amalia Children's Clinic, Isala Klinieken, Zwolle,

\#Beatrix Children's Hospital, University Medical Centre Groningen, and

"UMCG Postgraduate School of Medicine, University Medical Centre Groningen, Groningen, The Netherlands.

CORRESPONDENCE

E.P. de Groot

Princess Amalia Children's Clinic Isala Klinieken PO Box 10400 $8000 \mathrm{GK}$ Zwolle The Netherlands E-mail: e.p.de.groot@isala.nl 
and low parental expectations of the benefit of ICS treatment $[8,19]$ are associated with unsatisfactory asthma control despite ICS maintenance treatment. Conversely, correct inhalation technique and high adherence have been shown to contribute to achieving and maintaining good asthma control $[17,20,21]$. Observational evidence suggests that control of exposure to environmental triggers, such as tobacco smoke and relevant inhalant allergens [2, 20, 22], and comprehensive, repeated education and ongoing follow-up $[23,24]$ may help to improve asthma control. In fact, many children with "problematic severe asthma" [25] can achieve complete asthma control by improving adherence and correct inhalation technique [17], and by eliminating exposure to environmental triggers [20].

It seems likely, therefore, that achieving and maintaining asthma control should be possible in the large majority of children with asthma if a number of issues are consequently and comprehensively addressed in its management.

Although a considerable body of evidence is available on interventions to reduce exposure to environmental trigger factors, poor adherence to maintenance therapy and poor inhalation technique in children with asthma [23, 26-33], the issue of comorbidities in childhood asthma and their influence on asthma control has received relatively little attention in paediatric literature to date. In problematic severe asthma especially, the presence of comorbidities should be evaluated. In this article, we review the published evidence on the impact of comorbid medical conditions on the severity and control of childhood asthma.

\section{METHODS}

Studies were identified in PubMed, EMBASE and the Cochrane Library. The following keywords were used: "comorbidity", "asthma", "obesity", "allergic rhinitis", "food allergy", "dysfunctional breathing", " mental disorder", "anxiety", "depression", "GERD" or "gastro-oesophageal reflux disease", "treatment" and "diagnosis". The search was limited to "all child". The references in retrieved articles were scanned to find additional relevant papers. Because asthma in children $<4$ yrs of age is a different entity [3,34], we focused on studies in children between the age of 5 and 18 yrs. Comorbidity was defined as the presence of one or more disorders (or diseases) in addition to the primary disease asthma.

\section{RESULTS}

\section{Allergic rhinitis}

The prevalence of allergic rhinitis has increased in children over the past decades, and it now varies from $0.8 \%$ to $39.7 \%$, depending on country and age $[35,36]$. The majority of asthmatic children also have allergic rhinitis. Nevertheless, allergic rhinitis commonly goes unrecognised and undertreated in children with asthma [37].

The reported prevalence of allergic rhinitis in children with asthma is substantially higher than that in the general population, and ranges from $60 \%$ to $80 \%$ [37, 38]. SIMONS [39] stated that it is likely that asthma and allergic rhinitis frequently coexist because of their similarities in anatomy, physiology and immunopathology (table 1). Most patients with allergic rhinitis have symptoms, such as nasal itching, sneezing, increased nasal secretions and nasal obstruction. However, general symptoms such as lassitude, cough and sleepiness may also occur. If these are the presenting symptoms, the diagnosis of allergic rhinitis may be missed if the patient and parents are not actively questioned about the presence of nasal symptoms [35]. For example, in a recent study at Princess Amalia Children's Clinic (Isala Klinieken, Zwolle, The Netherlands) of 61 children referred for nonspecific cough and breathlessness, 13 (21\%) were diagnosed with allergic rhinitis [40].

Treatment of allergic rhinitis with intranasal corticosteroids is the first choice of therapy in adults [41, 42]. Literature regarding children is sparse. The few studies on intranasal steroids for allergic rhinitis in children show short-term improvement of nasal (sneezing, rhinorrhoea, obstruction and itching) and ocular symptoms $[43,44]$. It is reasonable to assume, therefore, that treatment of concurrent allergic rhinitis in children with asthma will reduce rhinitis symptoms. More challenging is the question as to whether treatment of allergic rhinitis also improves asthma control. In adults, the use of nasal corticosteroids was associated with a significantly reduced risk of asthma-related emergency room treatments and hospitalisations (adjusted OR 0.75 (95\% CI $0.62-0.91$ ) and 0.56 (95\% CI 0.42-0.76), respectively) [37, 45]. This has not yet been studied in children. Indirect evidence for poorer control of asthma in children with allergic rhinitis may come from greater health service utilisation and costs. It has been shown that asthmatic children with allergic rhinitis have more frequent emergency department visits and hospital admissions than children with asthma without allergic rhinitis [46]. Although this suggests that treatment of allergic rhinitis in children with asthma could improve asthma control, this hypothesis requires confirmation in a randomised controlled trial.

\section{Food allergy}

Food allergy is defined as an adverse immunological response to food that is reproducible under blinded conditions [47]. Previous studies suggest that the prevalence of food allergies in the general population is $\sim 8 \%$ in children aged $<3 \mathrm{yrs}$, and $\sim 2 \%$ in adults $[48,49]$. The incidence, reported in a study, of confirmed food-induced respiratory reactions is estimated to be between $2 \%$ and $8 \%$ in children and adults with asthma [50]. As

TABLE 1 Similarities in anatomy, physiology and immunopathology in asthma and allergic rhinitis

$\begin{array}{ll}\text { Anatomy } & \text { Chronology of embryological development. } \\ \text { Respiratory epithelium extends from the nasal fossa throughout the nasopharynx, larynx, trachea, bronchi and bronchioles } \\ \text { Nasal and bronchial hyperresponsiveness to environmental and chemical stimuli } \\ \text { Nasobronchial reflex from environmental stimuli } \\ \text { Immediate hypersensitivity and allergic responses and persistent allergic inflammation, characterised by eosinophilia occuring } \\ \text { in upper and lower airways } \\ \text { There is a systemic immune response to airborne allergens }\end{array}$




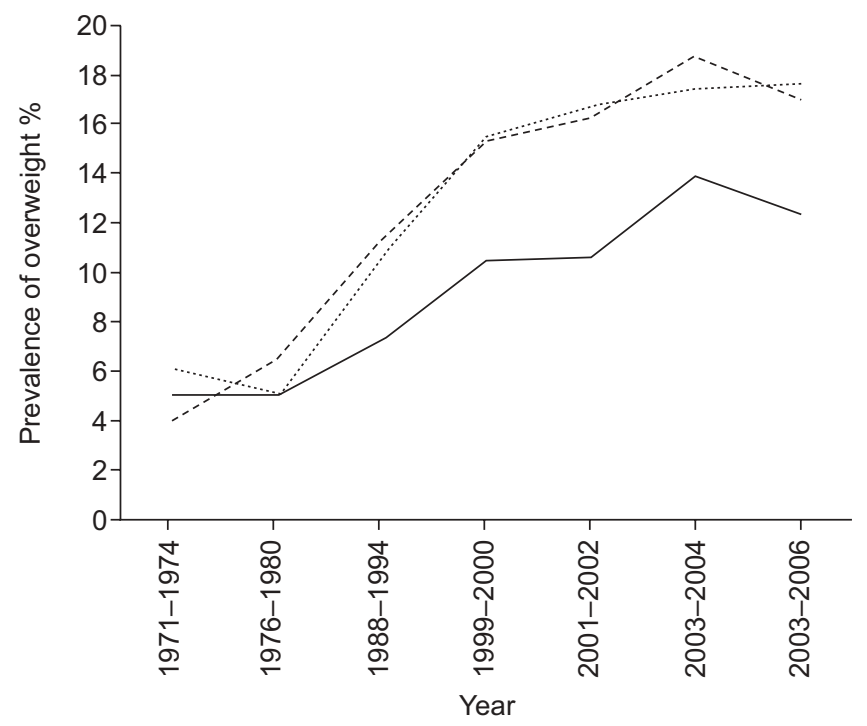

FIGURE 1. Increase in obesity in children in the USA as reported in the National Health and Nutrition Surveys. Modified from [54-56] with permission from the publisher. - : children aged 2-5 yrs; ---: children aged 6-11 yrs; $\cdots$ : children aged 12-19 yrs.

food allergy and asthma are both atopic diseases they may coexist, but asthma as the only manifestation of food allergy is rare and atypical [47, 48, 50]. Fatal or near fatal reactions (anaphylaxis) are more common in patients with asthma [48]. SICHERER et al. [51] showed that patients with asthma were more likely to have a severe reaction to food allergens than patients without asthma $(33 \%$ versus $21 \% ; \mathrm{p}<0.0001)$. In the $\mathrm{UK}$, all children $(n=8)$ with fatal anaphylaxis had a history of asthma [52]. In a retrospective study in children with asthma and food allergy, peanut and milk allergies were both associated with an increased number of hospitalisations for asthma [53].

Therefore, it seems that comorbid asthma in food allergy increases the risk of severe reactions, and that comorbid food allergy in asthma reduces asthma control.

\section{Obesity}

Overweight in children has become a major public health problem. Since the 1970s, prevalence rates have more than quadrupled in the USA in children aged 6-11 yrs, and have also sharply increased in children young than school age and adolescents (fig. 1) [57]. No pan-European data could be found although several studies from individual European countries report a similar rise in prevalence. For example, in the Netherlands in $1997,8.8 \%$ of boys and $11.8 \%$ of girls (5-17 yrs) were obese. This increased to $13.5 \%$ for boys and $16.7 \%$ for girls in 2002-2004 [58]. In Spain, overweight increased in both boys and girls from $4.4 \%$ and $2.9 \%$, respectively, in 1992 to $10.1 \%$ and $7.6 \%$, respectively, in 2004 [59]. Similarly, overweight in 12-yrold Finnish children increased from $12.8 \%$ in 1986 to $23.6 \%$ in 2006 [60]. Explanations for the rise in obesity in children include a decrease in physical activities, an increase in sedentary activities (watching television and playing computer games), an increase in food portions and the increased consumption of calorie-dense convenience foods [57].
Several studies show higher rates of asthma in children who are overweight [61-63]. A high body mass index (BMI) at 1-2 yrs was significantly associated with a higher prevalence of asthma symptoms at 3 yrs (OR $1.40(95 \%$ CI 1.12-1.73); $p=0.003)$, and a high BMI at 3-5 yrs was significantly associated with a higher prevalence of asthma symptoms at 6 yrs (OR 1.36 (95\% CI 1.03 1.79); $p=0.03$ ) [63]. This effect was particularly strong in females. For example, girls who became overweight or obese between 6 11 yrs of age were seven times more likely to develop new asthma symptoms at the age of 11 or 13 yrs $(p<0.01)$ [55]. Other studies found an association of overweight with exerciseinduced cough and wheeze, visits to the emergency department (39\% versus 31\%; $\mathrm{p}=0.04)$ and missed school days [64, 65]. Although the majority of studies have found an association between asthma and obesity, some did not find such a relation [66-68]. A possible explanation is that obese children could have asthma-like symptoms (shortness of breath) without having asthma. In addition, differences in the definition of asthma severity could play a role [67].

The possible mechanisms of the effect of obesity on asthma have been discussed in depth in a recent review, and are summarised in table 2 [69].

In a 12-yr follow-up study of very low birth-weight children, leptin was thought to play a role in the pathogenesis of both asthma and obesity [70]. Leptin levels were considerably higher in the overweight than in the non-overweight children (median value 18.1 versus $2.8 \mathrm{ng} \cdot \mathrm{mL}^{-1} ; \mathrm{p}<0.001$ ). In the overweight children, current asthmatics had leptin levels that were twice as high as children without current asthma (median value 30.8 versus $14.3 \mathrm{ng} \cdot \mathrm{mL}^{-1} ; \mathrm{p}=0.14$ ), which was not the case in the non-overweight children [70]. The association of obesity with serum leptin levels has been confirmed [71].

Suboptimal response to controller therapy (ICS) is a possible mechanism explaining why asthma could be more severe in obesity. In adults, an altered response to ICS has been shown in obese asthma patients. Elevated BMI was associated with blunted in vitro response to ICS in overweight and obese patients whilst this could not be shown in obese patients without asthma [72].

The association between obesity and asthma may also be partly explained by the influence of asthma on obesity. Exerciseinduced asthma may lead to avoidance of physical activity that can increase weight gain [73]. Thus, asthma and obesity can worsen each other [57]. A recent Norwegian study, however,

TABLE 2 Possible mechanisms of the effect of obesity on
asthma
Reduced lung volume and tidal volume in obesity that promote narrowing
of the airways
Low grade of inflammation may act on the lungs to exacerbate symptoms
Obesity-related changes in hormones
Dyslipidaemia
Gastro-oesophageal reflux
Sleep-disordered breathing
Type-2 diabetes
Hypertension


showed that adolescents with and without asthma did not differ in physical activity and energy intake [74]. In adults, there is evidence that weight reduction in obese asthmatic patients improves lung function, symptoms, morbidity and health status [75]. In children, the relationship between obesity and more severe asthma has not been demonstrated as clearly. Also dynamic mechanical factors are postulated to be involved. In obese individuals, breath frequency is increased and tidal volumes are reduced compared with non-obese individuals [76]. A forced extension of airway smooth muscle is provided by spontaneous tidal breathing which has been shown to have a bronchodilatory action [77]. Obese individuals without this bronchodilatory mechanism would be, as reported recently, expected to experience increased airway hyperresponsiveness [78]. Further research should improve our understanding on the relationship between asthma and obesity in children. Although it has not been shown conclusively that body weight reduction improves asthma control in obese children, this should not discourage physicians from trying to achieve weight loss in these patients, as the importance of weight control in overweight children has been clearly reviewed $[79,80]$.

\section{Dysfunctional breathing}

Dysfunctional breathing is defined as chronic or recurrent changes in breathing pattern, causing respiratory and nonrespiratory complaints [81]. Symptoms of dysfunctional breathing include dyspnoea with normal lung function, chest tightness, chest pain, deep sighing, exercise-induced breathlessness, frequent yawning and hyperventilation [82]. Hyperventilation or dysfunctional breathing has been reported in childhood [83-88], but its prevalence is unknown. There is no accepted gold standard of the diagnosis of dysfunctional breathing beyond the clinical description, but the Nijmegen Questionnaire is a symptom checklist (table 3 ) that can be used to discriminate dysfunctional breathers from normal individuals in adults [89]. In a random sample of 300 adults without asthma from the medical

\begin{tabular}{l} 
TABLE 3 Nijmegen Questionnaire symptom checklist \\
Chest pain \\
Feeling tense \\
Blurred vision \\
Dizzy spells \\
To be confused, losing touch with environment \\
Accelerated or deepened breathing \\
Shortness of breath \\
Constricted chest \\
Bloated abdominal sensation \\
Tingling fingers \\
Unable to breath deeply \\
Stiffness of fingers or arms \\
Tightness around the mouth \\
Cold hands or feet \\
Palpitations \\
Feeling of anxiety \\
\hline
\end{tabular}

Each item scores 0 (never) to 4 (very often) points. When the Nijmegen Questionnaire score is $\geqslant 23$, the diagnosis of dysfunctional breathing is $80 \%$ certain. Modified from [65] with permission from the publisher. records of a UK semirural general practice, $8 \%$ of patients showed positive screening scores for dysfunctional breathing [90]. In the same study, $29 \%$ of asthmatics showed positive screening scores for dysfunctional breathing [90]. This indicates that dysfunctional breathing is more prevalent in adults with asthma than in healthy controls. Approximately one third of females and a fifth of males with asthma had scores suggestive of dysfunctional breathing (table 4) [91].

In a randomised controlled trial in adults with symptoms suggestive of dysfunctional breathing, a clinically relevant improvement in quality of life was found following a brief physiotherapy intervention. This improvement was maintained for 6 months after the intervention in $25 \%$ of patients [82].

The application of the Nijmegen Questionnaire in the context of asthma in children requires further exploration [81]. It has been described, both by us and by others, that there are children with troublesome breathlessness during or after exercise, in whom lung function remains normal during exercise testing [86-88, 92]. It has been our experience that most of these patients benefit from physiotherapy aimed at relaxation and at maintaining a normal breathing pattern [93]. These preliminary observations need confirmation and further exploration in rigorously designed further studies.

\section{Vocal cord dysfunction}

Vocal cord dysfunction (VCD) syndrome is a functional disorder of the vocal cords [94], characterised by the inappropriate adduction of the vocal cords during inspiration. Two phenotypes of VCD syndrome have been described [95]. One type occurs spontaneously, with the patient experiencing dyspnoea and inspiratory stridor (often described as "wheezing") at various and often unpredictable times, thus mimicking asthma. The other phenotype only occurs with exercise. Flexible fiberoptic endoscopy while the patient is symptomatic is the gold standard for the diagnosis of VCD. The prevalence of VCD in children is unknown. Vocal cord dysfunction should be evaluated as a possible comorbid condition in difficult asthma.

\section{Mental disorders}

Childhood depressive illnesses, including major depressive disorder and dysthymia, are recurrent, often chronic conditions with significant morbidity and mortality [96, 97]. Population studies of children and adolescents in the USA and in Europe have reported prevalence rates of depression ranging between $0.14 \%$ and $2.5 \%$ in children and 0.45 to $8.3 \%$ in adolescents [96-98]. KATON et al. [99] interviewed 781 subjects aged 11-17 yrs who were diagnosed with asthma and

\begin{tabular}{|c|c|c|c|}
\hline TABLE 4 & $\begin{array}{l}\text { Adults with posi } \\
\text { breathing by ag }\end{array}$ & $\begin{array}{l}\text { e scores for } 0 \\
\text { and sex }\end{array}$ & ctional \\
\hline & Aged $<40$ yrs & Aged $>40$ yrs & Total \\
\hline Males & $7 / 25$ (28) & $10 / 62(16)$ & $17 / 87(20)$ \\
\hline Females & $14 / 38(37)$ & 32/94 (34) & 46/132 (35) \\
\hline Total & 21/63 (33) & $42 / 165$ (27) & $63 / 219$ (29) \\
\hline
\end{tabular}




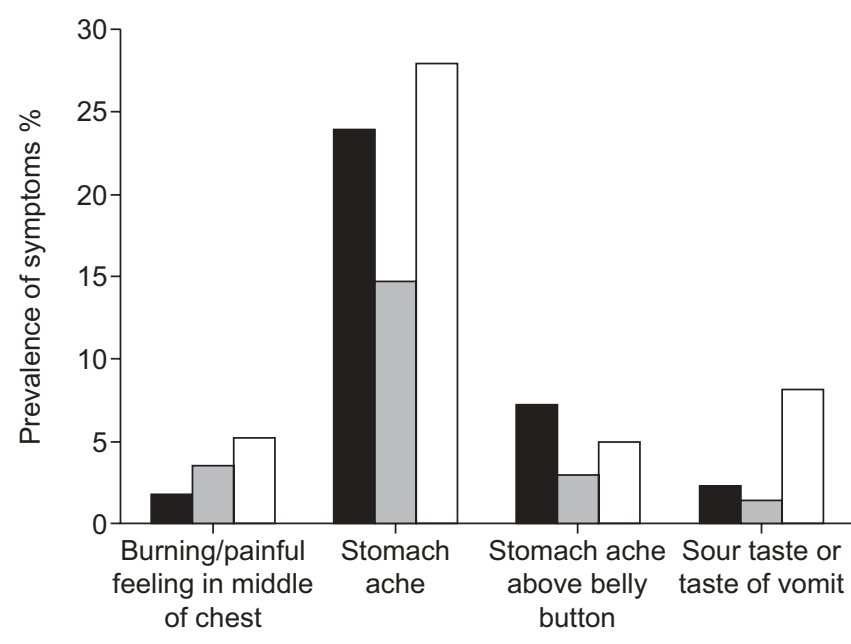

FIGURE 2. Percentage of reported gastro-oesophageal reflux symptoms in the past week. (adapted from NeLSON et al.) [106]. - : reported by parents of children aged 3-9 yrs ( $\mathrm{n}=566)$; 1 : reported by parents of children aged 10-17 yrs $(n=584) ; \square$ : reported by children aged 10-17 yrs $(n=615)$.

compared them to a group of matched non-asthmatics. They found that $16.3 \%$ of the children with asthma met the Diagnostic and Statistical Manual of Mental Disorders (DSM)-IV criteria for one or more anxiety or depressive disorders in the previous 12 months, compared with $8.6 \%$ of those without asthma $(\mathrm{p}<0.01)$. Higher trait anxiety has been associated with increased perception of asthma symptoms in children, especially in mild asthma [100]. Both over perception of asthma symptoms and blunted perception of symptoms may play a role in maintaining poor asthma control, and hamper successful management [100]. In adults, increasing levels of depression have been associated with increased emergency department visits, hospitalisations, and unscheduled healthcare visits for asthma [101, 102]. In children, negative affect scores are related to asthma symptom scores in a dose-dependent fashion [19].

The scanty literature on depressive disorders in children with asthma suggests that it may commonly go unrecognised and untreated. For example, even if mental disorders are recognised in the assessment of children with asthma, only one in five of these patients received an adequate dosage and duration of antidepressant medication, and only one in six received an adequate number of psychotherapy sessions [103]. More children should be identified as at risk and prevented or treated for this co-morbidity [104].

\section{Gastro-oesophageal reflux}

The prevalence of gastro-oesophageal reflux disease (GERD) has been poorly studied in children [105]. One cross-sectional survey in the USA in children aged 3-17 yrs of age showed that $1-18 \%$ of children had symptoms of GERD, depending on the severity or frequency queried (fig. 2) [106]. GUSTAFSSON et al. [107] showed that oesophageal dysfunction occurred more frequently in $8-19-y r-o l d$ asthmatics than in controls $(60 \%$ versus $14 \% ; \mathrm{p}<0.01)$, and that acid reflux was found in $50 \%$ of these asthmatic teenagers [108]. A systematic review on the prevalence of GERD in children with asthma reported prevalence rates ranging from $19.3 \%$ to $65 \%$ [109]. These findings were supported in a recent study in 30 children with non-atopic asthma, $21(70 \%)$ of which showed GERD using extended oesophageal $\mathrm{pH}$ monitoring [110]. One study compared the prevalence of asthma in 1,980 children $>2$ yrs of age with GERD to 7,920 controls without GERD. The prevalence of diagnosed asthma in children with GERD was twice the prevalence of that in controls (13.2\% versus. $6.8 \%$; $<<0.0001)$ [111].

Although asthma and GERD in children appear to be related, a causal relationship between the two disorders has not yet been established. Whether it is asthma that causes reflux, reflux that causes asthma, or is there no clinically relevant relationship remains unclear. An oral challenge with $200 \mathrm{~mL}$ diluted $\mathrm{HCl}$ in children with asthma increased histamine sensitivity $(p=0.001)$ although baseline peak flow did not change [112]. A populationbased birth cohort showed that the association between reflux symptoms and respiratory symptoms in young adults was independent of BMI [113]. Overweight did not explain the higher frequency of GERD in asthma patients [114].

Very few studies have examined the effect of GERD therapy on asthma [106]. One short-term study (12 weeks) in children showed no improvement in asthma symptoms [115]. In another study, a reduction in asthma exacerbations was found in children with asthma and GERD when treated with proton pump inhibitor and pro-kinetic agents for 12 months compared with treatment with ranitidine alone ( 0.33 versus 2.2 exacerbations.patient $\left.{ }^{-1} ; \mathrm{p}<0.05\right)$ [116]. KHOSHOO et al. [110] found a reduction in bronchial hyperreactivity after 2 yrs of GERD treatment in a group of non-atopic asthma patients, but no control group was used. Similarly, in children with asthma and GERD, a modest reduction in nocturnal asthma symptoms was observed during ranitidine treatment [117]. A recent review on treatment of GERD in asthma did not identify additional high quality studies [118]. Further high-quality randomised controlled trials on the treatment of GERD in asthma in children are needed before any firm conclusion can be drawn on the usefulness of such therapy in children with asthma.

\section{CONCLUSION}

As in adults, comorbidities are present in children with asthma. Although the evidence of the impact of comorbidities on childhood asthma is poor, clinicians should be aware of the high likelihood of comorbid disorders in children with asthma, and should actively screen asthmatic children, in particular those with troublesome or uncontrolled asthma, for the presence of overweight, allergic rhinitis, dysfunctional breathing, depressive disorders and, perhaps, gastro-oesophageal reflux. When comorbid conditions are recognised and treated adequately, better asthma control may be obtained.

\section{STATEMENT OF INTEREST}

A statement of interest for E.J. Duiverman can be found at www.erj. ersjournals.com $/ \mathrm{misc} /$ statements.dtl

\section{REFERENCES}

1 British Thoracic Society, Scottish Intercollediate Guidelines Network, British Guideline on the Management of Asthma. Thorax 2008; 63: Suppl. 4, iv1-iv121.

2 Global Initiative for Asthma. Global strategy for asthma management and prevention. www.ginasthma.com/GuidelineItem. asp?intId $=60$ Date last updated: 2008. 
3 Reddel HK, Taylor DR, Bateman ED, et al. An official American Thoracic Society/European Respiratory Society statement: asthma control and exacerbations: standardizing endpoints for clinical asthma trials and clinical practice. Am J Respir Crit Care Med 2009; 180: 59-99.

4 Adams NP, Jones PW. The dose-response characteristics of inhaled corticosteroids when used to treat asthma: an overview of Cochrane systematic reviews. Respir Med 2006; 100: 1297-1306.

5 British Thoracic Society, Scottish Intercollediate Guidelines Network, British guideline on the management of asthma. Thorax 2003; 58: Suppl. 1, i1-i94.

6 Kuehni CE, Frey U. Age-related differences in perceived asthma control in childhood: guidelines and reality. Eur Respir J 2002; 20: 880-889.

7 Rabe KF, Adachi M, Lai CK, et al. Worldwide severity and control of asthma in children and adults: the global asthma insights and reality surveys. J Allergy Clin Immunol 2004; 114: $40-47$.

8 Smith LA, Bokhour B, Hohman KH, et al. Modifiable risk factors for suboptimal control and controller medication underuse among children with asthma. Pediatrics 2008; 122: 760-769.

9 Weinberger M. Seventeen years of asthma guidelines: why hasn't the outcome improved for children? J Pediatr 2009; 154: 786-788.

10 Wennergren G, Strannegard IL. Asthma hospitalizations continue to decrease in schoolchildren but hospitalization rates for wheezing illnesses remain high in young children. Acta Paediatr 2002; 91: 1239-1245.

11 Wennergren G, Kristjansson S, Strannegard IL. Decrease in hospitalization for treatment of childhood asthma with increased use of antiinflammatory treatment, despite an increase in prevalence of asthma. J Allergy Clin Immunol 1996; 97: 742-748.

12 Malmstrom K, Korhonen K, Kaila M, et al. Acute childhood asthma in Finland: a retrospective review of hospital admissions from 1976 to 1995. Pediatr Allergy Immunol 2000; 11: 236-240.

13 Hjern A, Haglund B, Bremberg S, et al. Social adversity, migration and hospital admissions for childhood asthma in Sweden. Acta Paediatr 1999; 88: 1107-1112.

14 Engelsvold DH, Oymar K. Hospital admissions for childhood asthma in Rogaland, Norway, from 1984 to 2000. Acta Paediatr 2003; 92: 610-616.

15 Saynajakangas $\mathrm{O}$, Valmari $\mathrm{P}$, Tuuponen $\mathrm{T}$, et al. Trends in hospitalization for childhood asthma in Finland in 1996-2004. Acta Paediatr 2007; 96: 919-923.

16 Priftis K, Panagiotopoulou-Gartagani P, Tapratzi-Potamianou P, et al. Hospitalizations for childhood asthma in Athens, Greece, from 1978 to 2000. Pediatr Allergy Immunol 2005; 16: 82-85.

17 Kamps AW, Brand PL, Kimpen JL, et al. Outpatient management of childhood asthma by paediatrician or asthma nurse: randomised controlled study with one year follow up. Thorax 2003; 58: 968-973.

18 Lasmar L, Camargos P, Champs NS, et al. Adherence rate to inhaled corticosteroids and their impact on asthma control. Allergy 2009; 64: 784-789.

19 Bender B, Zhang L. Negative affect, medication adherence, and asthma control in children. J Allergy Clin Immunol 2008; 122: 490-495.

20 De Boeck BK, Moens M, Van Der AN, et al. "Difficult asthma": can symptoms be controlled in a structured environment? Pediatr Pulmonol 2009; 44: 743-748.

21 Gruchalla RS, Sampson HA, Matsui E, et al. Asthma morbidity among inner-city adolescents receiving guidelines-based therapy: role of predictors in the setting of high adherence. J Allergy Clin Immunol 2009; 124: 213-221.

22 Morgan WJ, Crain EF, Gruchalla RS, et al. Results of a homebased environmental intervention among urban children with asthma. N Engl J Med 2004; 351: 1068-1080.
23 Brouwer AF, Brand PL. Asthma education and monitoring: what has been shown to work. Paediatr Respir Rev 2008; 9: 193-199.

24 Bracken $\mathrm{M}$, Fleming $\mathrm{L}$, Hall $\mathrm{P}$, et al. The importance of nurse-led home visits in the assessment of children with problematic asthma. Arch Dis Child 2009; 94: 780-784.

25 Bush A, Hedlin G, Carlsen KH, et al. Severe childhood asthma: a common international approach? Lancet 2008; 372: 1019-1021.

26 Platts-Mills TA, Erwin EA, Heymann PW, et al. Pro: the evidence for a causal role of dust mites in asthma. Am J Respir Crit Care Med 2009; 180: 109-113.

27 Custovic A, Wijk RG. The effectiveness of measures to change the indoor environment in the treatment of allergic rhinitis and asthma: ARIA update (in collaboration with GA(2)LEN). Allergy 2005; 60: 1112-1115.

28 Spencer N, Blackburn C, Bonas S, et al. Parent reported home smoking bans and toddler (18-30 month) smoke exposure: a cross-sectional survey. Arch Dis Child 2005; 90: 670-674.

29 Johansson A, Hermansson G, Ludvigsson J. How should parents protect their children from environmental tobacco-smoke exposure in the home? Pediatrics 2004; 113: e291-e295.

30 Curry SJ, Ludman EJ, Graham E, et al. Pediatric-based smoking cessation intervention for low-income women: a randomized trial. Arch Pediatr Adolesc Med 2003; 157: 295-302.

31 Borrelli B, Riekert KA, Weinstein A, et al. Brief motivational interviewing as a clinical strategy to promote asthma medication adherence. J Allergy Clin Immunol 2007; 120: 1023-1030.

32 Charles T, Quinn D, Weatherall $\mathrm{M}$, et al. An audiovisual reminder function improves adherence with inhaled corticosteroid therapy in asthma. J Allergy Clin Immunol 2007; 119: 811-816.

33 Kamps AW, Roorda RJ, Kimpen JL, et al. Impact of nurse-led outpatient management of children with asthma on healthcare resource utilisation and costs. Eur Respir J 2004; 23: 304-309.

34 Global Initiative for Asthma (GINA). Global Strategy for the Diagnosis and Management of Asthma in Children 5 Years and Younger. Updated 2009. www.ginasthma.com/GuidelineItem. asp?? $11=2 \& \$ 2=1 \&$ intId $=1689$

35 de Groot H, Brand PL, Fokkens WF, et al. Allergic rhinoconjunctivitis in children. BMJ 2007; 335: 985-988.

36 Asher MI, Montefort S, Bjorksten B, et al. Worldwide time trends in the prevalence of symptoms of asthma, allergic rhinoconjunctivitis, and eczema in childhood: ISAAC Phases One and Three repeat multicountry cross-sectional surveys. Lancet 2006; 368: 733-743.

37 Hamouda S, Karila C, Connault T, et al. Allergic rhinitis in children with asthma: a questionnaire-based study. Clin Exp Allergy 2008; 38: 761-766.

38 Masuda S, Fujisawa T, Katsumata H, et al. High prevalence and young onset of allergic rhinitis in children with bronchial asthma. Pediatr Allergy Immunol 2008; 19: 517-522.

39 Simons FER. What's in a name? The allergic rhinitis-asthma connection. Clin Exp Allergy Rev 2003; 3: 9-17.

40 Brouwer AF, Visser CAN, Duiverman EJ, et al. Is home spirometry useful in diagnosing asthma in children with nonspecific respiratory symptoms? Pediatr Pulmonol 2010; 45: 326-332.

41 Weiner JM, Abramson MJ, Puy RM. Intranasal corticosteroids versus oral $\mathrm{H} 1$ receptor antagonists in allergic rhinitis: systematic review of randomised controlled trials. BMJ 1998; 317: 1624-1629.

42 Wood RA, Eggleston PA. The effects of intranasal steroids on nasal and pulmonary responses to cat exposure. Am J Respir Crit Care Med 1995; 151: 315-320.

43 Dhillon S, Wagstaff AJ. Ciclesonide nasal spray: in allergic rhinitis. Drugs 2008; 68: 875-883.

44 McCormack PL, Scott LJ. Fluticasone furoate: intranasal use in allergic rhinitis. Drugs 2007; 67: 1905-1915. 
45 Corren J, Manning BE, Thompson SF, et al. Rhinitis therapy and the prevention of hospital care for asthma: a case-control study. J Allergy Clin Immunol 2004; 113: 415-419.

46 Kang HY, Park CS, Bang HR, et al. Effect of allergic rhinitis on the use and cost of health services by children with asthma. Yonsei Med J 2008; 49: 521-529.

47 Ozol D, Mete E. Asthma and food allergy. Curr Opin Pulm Med 2008; 14: 9-12.

48 Beausoleil JL, Fiedler J, Spergel JM. Food intolerance and childhood asthma: what is the link? Paediatr Drugs 2007; 9 : 157-163.

49 Nauta AJ, Engels F, Knippels LM, et al. Mechanisms of allergy and asthma. Eur J Pharmacol 2008; 585: 354-360.

50 James JM. Respiratory manifestations of food allergy. Pediatrics 2003; 111: 1625-1630.

51 Sicherer SH, Furlong TJ, Munoz-Furlong A, et al. A voluntary registry for peanut and tree nut allergy: characteristics of the first 5149 registrants. J Allergy Clin Immunol 2001; 108: 128-132.

52 Macdougall CF, Cant AJ, Colver AF. How dangerous is food allergy in childhood? The incidence of severe and fatal allergic reactions across the UK and Ireland. Arch Dis Child 2002; 86: 236-239.

53 Simpson AB, Glutting J, Yousef E. Food allergy and asthma morbidity in children. Pediatr Pulmonol 2007; 42: 489-495.

54 Ogden CL, Carroll MD, Flegal KM. High body mass index for age among US children and adolescents, 2003-2006. JAMA 2008; 299: 2401-2405.

55 Ogden CL, Flegal KM, Carroll MD, et al. Prevalence and trends in overweight among US children and adolescents, 1999-2000. JAMA 2002; 288: 1728-1732.

56 Ogden CL, Carroll MD, Curtin LR, et al. Prevalence of overweight and obesity in the United States, 1999-2004. JAMA 2006; 295: 1549-1555.

57 Kopel SJ, Klein RB. Childhood asthma and obesity. Med Health $R$ I 2008; 91: 161-164.

58 Harbers MM, van der Wilk EA, de Beer J. Differences between The Netherlands and other countries? www.nationaalkompas. nl/bevolking/verschillen-internationaal/ Date last accessed: February 17 2010. Date last updated: December 82009.

59 Martinez-Vizcaino V, Sanchez LM, Moya MP, et al. Trends in excess weight and thinness among Spanish schoolchildren in the period 1992-2004: the Cuenca study. Public Health Nutr 2009; 12 1015-1018.

60 Vuorela N, Saha MT, Salo M. Prevalence of overweight and obesity in 5- and 12-year-old Finnish children in 1986 and 2006. Acta Paediatr 2009; 98: 507-512.

61 Schaub B, von Mutius E. Obesity and asthma, what are the links? Curr Opin Allergy Clin Immunol 2005; 5: 185-193.

62 Castro-Rodriguez JA, Holberg CJ, Morgan WJ, et al. Increased incidence of asthmalike symptoms in girls who become overweight or obese during the school years. Am J Respir Crit Care Med 2001; 163: 1344-1349.

63 Scholtens S, Wijga AH, Seidell JC, et al. Overweight and changes in weight status during childhood in relation to asthma symptoms at 8 years of age. J Allergy Clin Immunol 2009; 123: 1312-1318

64 Belamarich PF, Luder E, Kattan M, et al. Do obese inner-city children with asthma have more symptoms than nonobese children with asthma? Pediatrics 2000; 106: 1436-1441.

65 Tantisira KG, Weiss ST. Complex interactions in complex traits: obesity and asthma. Thorax 2001; 56: Suppl. 2, ii64-ii73.

66 Schachter LM, Peat JK, Salome CM. Asthma and atopy in overweight children. Thorax 2003; 58: 1031-1035.

67 Brenner JS, Kelly CS, Wenger AD, et al. Asthma and obesity in adolescents: is there an association? J Asthma 2001; 38: 509-515.

68 Story RE. Asthma and obesity in children. Curr Opin Pediatr 2007; 19: 680-684.
69 Shore SA. Obesity and asthma: possible mechanisms. J Allergy Clin Immunol 2008; 121: 1087-1093.

70 Mai XM, Bottcher MF, Leijon I. Leptin and asthma in overweight children at 12 years of age. Pediatr Allergy Immunol 2004; 15: 523-530.

71 Guler N, Kirerleri E, Ones U, et al. Leptin: does it have any role in childhood asthma? J Allergy Clin Immunol 2004; 114: 254-259.

72 Sutherland ER, Goleva E, Strand M, et al. Body mass and glucocorticoid response in asthma. Am J Respir Crit Care Med 2008; 178: 682-687.

73 Milgrom H, Taussig LM. Keeping children with exerciseinduced asthma active. Pediatrics 1999; 104: e38.

74 Berntsen S, Carlsen KC, Anderssen SA, et al. Norwegian adolescents with asthma are physical active and fit. Allergy 2009; 64: 421-426.

75 Stenius-Aarniala B, Poussa T, Kvarnstrom J, et al. Immediate and long term effects of weight reduction in obese people with asthma: randomised controlled study. BMJ 2000; 320: 827-832.

76 Sampson MG, Grassino AE. Load compensation in obese patients during quiet tidal breathing. J Appl Physiol 1983; 55: 1269-1276.

77 Fredberg JJ, Inouye DS, Mijailovich SM, et al. Perturbed equilibrium of myosin binding in airway smooth muscle and its implications in bronchospasm. Am J Respir Crit Care Med 1999; 159: 959-967.

78 Lucas SR, Platts-Mills TA. Paediatric asthma and obesity. Paediatr Respir Rev 2006; 7: 233-238

79 Reilly JJ, Methven E, McDowell ZC, et al. Health consequences of obesity. Arch Dis Child 2003; 88: 748-752.

80 Whitlock EP, Williams SB, Gold R, et al. Screening and interventions for childhood overweight: a summary of evidence for the US Preventive Services Task Force. Pediatrics 2005; 116 e125-e144.

81 Morgan MD. Dysfunctional breathing in asthma: is it common, identifiable and correctable? Thorax 2002; 57: Suppl. 2, 1131-1135.

82 Thomas M, McKinley RK, Freeman E, et al. Breathing retraining for dysfunctional breathing in asthma: a randomised controlled trial. Thorax 2003; 58: 110-115.

83 Enzer NB, Walker PA. Hyperventilation syndrome in childhood A review of 44 cases. J Pediatr 1967; 70: 521-532.

84 Baranes $T$, Rossignol B, Stheneur C, et al. [Hyperventilation syndrome in children.] Arch Pediatr 2005; 12: 1742-1747.

85 Herman SP, Stickler GB, Lucas AR. Hyperventilation syndrome in children and adolescents: long-term follow-up. Pediatrics 1981; 67: 183-187.

86 Brouwer AF, Roorda RJ, van Reijn DA, et al Inspanningsgebonden benauwdheid bij kinderen: disfunctionele ademhaling? [Exercise induced dyspnoea in children: dysfunctional breathing?] Tijdschr Kindergeneeskd 2004; 72: 209-212.

87 Abu-Hassan M, Tannous B, Weinberger M. Exercise induced dyspnea in children and adolescents: if not asthma then what? Ann Allergy Asthma Immunol 2005; 94: 366-371.

88 Seear M, Wensley D, West N. How accurate is the diagnosis of exercise induced asthma among Vancouver schoolchildren? Arch Dis Child 2005; 90: 898-902.

89 van Dixhoorn DJ, Duivenvoorden HJ. Efficacy of Nijmegen Questionnaire in recognition of the hyperventilation syndrome. J Psychosom Res 1985; 29: 199-206.

90 Thomas M, McKinley RK, Freeman E, et al. The prevalence of dysfunctional breathing in adults in the community with and without asthma. Prim Care Respir J 2005; 14: 78-82.

91 Thomas M, McKinley RK, Freeman E, et al. Prevalence of dysfunctional breathing in patients treated for asthma in primary care: cross sectional survey. BMJ 2001; 322: 1098-1100.

92 De Baets F, Bodart E, Dramaix-Wilmet M, et al. Exercise-induced respiratory symptoms are poor predictors of bronchoconstriction. Pediatr Pulmonol 2005; 39: 301-305. 
93 Brouwer AF, Roorda RJ, Brand PL. [Treatment of asthma in children: more than merely "puffing".] Ned Tijdschr Geneeskd 2004; 148: 865-868.

94 Weinberger M, Abu-Hasan M. Pseudo-asthma: when cough, wheezing, and dyspnea are not asthma. Pediatrics 2007; 120: 855-864.

95 Doshi DR, Weinberger MM. Long-term outcome of vocal cord dysfunction. Ann Allergy Asthma Immunol 2006; 96: 794-799.

96 Ford T, Goodman R, Meltzer H. The British Child and Adolescent Mental Health Survey 1999: the prevalence of DSM-IV disorders. J Am Acad Child Adolesc Psychiatry 2003; 42: 1203-1211.

97 Galil N. Depression and asthma in children. Curr Opin Pediatr 2000; 12: 331-335.

98 Sorensen MJ, Thomsen PH. [Depression in children and adolescents.] Ugeskr Laeger 2006; 168: 679-682.

99 Katon W, Lozano P, Russo J, et al. The prevalence of DSM-IV anxiety and depressive disorders in youth with asthma compared with controls. J Adolesc Health 2007; 41: 455-463.

100 Chen E, Hermann C, Rodgers D, et al. Symptom perception in childhood asthma: the role of anxiety and asthma severity. Health Psychol 2006; 25: 389-395.

101 Mancuso CA, Peterson MG, Charlson ME. Effects of depressive symptoms on health-related quality of life in asthma patients. J Gen Intern Med 2000; 15: 301-310.

102 Eisner MD, Katz PP, Lactao G, et al. Impact of depressive symptoms on adult asthma outcomes. Ann Allergy Asthma Immunol 2005; 94: 566-574.

103 Katon WJ, Richardson L, Russo J, et al. Quality of mental health care for youth with asthma and comorbid anxiety and depression. Med Care 2006; 44: 1064-1072.

104 Glazebrook C, McPherson AC, Macdonald IA, et al. Asthma as a barrier to children's physical activity: implications for body mass index and mental health. Pediatrics 2006; 118: 2443-2449.

105 Chawla S, Seth D, Mahajan P, et al. Gastroesophageal reflux disorder: a review for primary care providers. Clin Pediatr (Phila) 2006; 45: 7-13.

106 Nelson SP, Chen EH, Syniar GM, et al. Prevalence of symptoms of gastroesophageal reflux during childhood: a pediatric practice-based survey. Pediatric Practice Research Group. Arch Pediatr Adolesc Med 2000; 154: 150-154.
107 Gustafsson PM, Kjellman NI, Tibbling L. Oesophageal function and symptoms in moderate and severe asthma. Acta Paediatr Scand 1986; 75: 729-736.

108 Gustafsson PM, Kjellman NI, Tibbling L. Bronchial asthma and acid reflux into the distal and proximal oesophagus. Arch Dis Child 1990; 65: 1255-1258.

109 Tolia V, Vandenplas Y. Systematic review: the extra-oesophageal symptoms of gastro-oesophageal reflux disease in children. Aliment Pharmacol Ther 2009; 29: 258-272.

110 Khoshoo V, Mohnot S, Haydel R Jr, et al. Bronchial hyperreactivity in non-atopic children with asthma and reflux: effect of anti-reflux treatment. Pediatr Pulmonol 2009; 44: 1070-1074.

111 El Serag HB, Gilger M, Kuebeler $M$, et al. Extraesophageal associations of gastroesophageal reflux disease in children without neurologic defects. Gastroenterology 2001; 121: 1294-1299.

112 Wilson NM, Charette L, Thomson AH, et al. Gastro-oesophageal reflux and childhood asthma: the acid test. Thorax 1985; 40: 592-597.

113 Hancox RJ, Poulton R, Taylor DR, et al. Associations between respiratory symptoms, lung function and gastro-oesophageal reflux symptoms in a population-based birth cohort. Respir Res 2006; 7: 142

114 Stordal K, Johannesdottir GB, Bentsen BS, et al. Asthma and overweight are associated with symptoms of gastro-oesophageal reflux. Acta Paediatr 2006; 95: 1197-1201.

115 Stordal K, Johannesdottir GB, Bentsen BS, et al. Acid suppression does not change respiratory symptoms in children with asthma and gastro-oesophageal reflux disease. Arch Dis Child 2005; 90: 956-960.

116 Khoshoo V, Haydel R Jr. Effect of antireflux treatment on asthma exacerbations in nonatopic children. J Pediatr Gastroenterol Nutr 2007; 44: 331-335.

117 Gustafsson PM, Kjellman NI, Tibbling L. A trial of ranitidine in asthmatic children and adolescents with or without pathological gastro-oesophageal reflux. Eur Respir J 1992; 5: 201-206.

118 Sopo SM, Radzik D, Calvani M. Does treatment with proton pump inhibitors for gastroesophageal reflux disease (GERD) improve asthma symptoms in children with asthma and GERD? A systematic review. J Investig Allergol Clin Immunol 2009; 19: 1-5. 